\title{
STOCHASTIC LEONTIEF TYPE EQUATIONS WITH IMPULSE ACTIONS
}

E.Yu. Mashkov, Southwest State University, Kursk, Russian Federation, mashkovevgen@yandex.ru

By a stochastic Leontief type equation we mean a special class of stochastic differential equations in the Ito form, in which there is a degenerate constant linear operator in the left-hand side and a non-degenerate constant linear operator in the right-hand side. In addition, in the right-hand side there is a deterministic term that depends only on time, as well as impulse effects. It is assumed that the diffusion coefficient of this system is given by a square matrix, which depends only on time. To study the equations under consideration, it is required to consider derivatives of sufficiently high orders from the free terms, including the Wiener process. In connection with this, to differentiate the Wiener process, we apply the machinery of Nelson mean derivatives of random processes, which makes it possible to avoid using the theory of generalized functions to the study of equations. As a result, analytical formulas are obtained for solving the equation in terms of mean derivatives of random processes.

Keywords: mean derivative; current velocity; Wiener process; stochastic Leontief type equation.

\section{Introduction}

We study the system of stochastic differential equations in $R^{n}$ of the form

$$
\tilde{L} \xi(t)=\tilde{M} \int_{0}^{t} \xi(s) d s+\int_{0}^{t} f(s) d s+Q \zeta(t)+\int_{0}^{t} P(s) d w(s), 0 \leq t \leq T,
$$

where $\tilde{L}$ and $\tilde{M}$ are degenerate and nondegenerate $n \times n$ matrices, respectively, forming a regular pencil, $Q$ is an $n \times n$ matrix, $\zeta(t)$ is an $n$-dimensional process of jumps, $P(t)$ is a sufficiently smooth $n \times n$ matrix, $f(t)$ is a sufficiently smooth time-dependent deterministic vector function, $w(t)$ is a Wiener process, $\xi(t)$ is the random process we are looking for.

With the use of systems of the Leontief type in the works by A.L. Shestakov, G.A. Sviridyuk and A.V. Keller [1-3] dynamic distortion of signals in radio devices is investigated. In the works by O. Schein, G. Denk [4], T. Sickenberger, R. Winkler [5,6] the systems under consideration arise in the mathematical modelling of oscillations and electric circuits. These equations arise in the works of L.A. Vlasenko et al $[7,8]$ in the mathematical modelling of the dynamics of corporation enterprises when using investment. We also mention the work by A.A. Belova, A.P. Kurdyukova [9], in which numerous applications of the systems under consideration are described.

To study this class of equations, it is required to consider higher-order derivatives of free terms, in this case the deterministic term and the Wiener process or white noise. It is known that the derivatives of the Wiener process exist only in the sense of generalized functions, which are extremely difficult to use in these equations. This circumstance makes a direct investigation of our system complicated. In this connection, we note the work by L.A. Vlasenko and others [8], in which restrictions on the coefficients of the equation are 
introduced, which make it possible not to use the "derivatives" of the Wiener process. Here we carry out the study of the equation without resorting to these limitations.

Following [10,11], in which this class of equations with a variable diffusion coefficient and without impulsive influences on the right-hand side was studied, we use the machinery of the Nelson mean derivatives of random processes to study the solutions of the equations under consideration, for the description of which generalized functions are not applied. Namely, we apply the symmetric mean derivatives (the current velocities) of the Wiener process. Current velocities, according to the general ideology of mean derivatives, are natural analogues of the physical velocities of deterministic processes. As a result, for the system under consideration, we obtain physically meaningful formulas for solutions in terms of symmetric mean derivatives of random processes.

\section{Mean Derivatives}

We consider the stochastic process $\xi(t)$ in $R^{n}, t \in[0, T]$, defined on a certain probability space $(\Omega, \mathcal{F}, \mathrm{P})$ and such that $\xi(t)$ is an $L_{1}$-random element for every $t$. It is known that every such a process generates a family of $\sigma$-subalgebras of $\sigma$-algebra $\mathcal{F}$ called "present" and denoted by $\mathcal{N}_{t}^{\xi}$. It is the minimal $\sigma$-algebra that includes all preimages of Borel sets from $R^{n}$. We suppose $\mathcal{N}_{t}^{\xi}$ to be complete, that is, it is completed by all sets of probability zero.

For convenience, we denote the conditional expectation $E\left(\cdot \mid \mathcal{N}_{t}^{\xi}\right)$ relative to the "present" $\mathcal{N}_{t}^{\xi}$ for $\xi(t)$ by $E_{t}^{\xi}$. The usual ("unconditional") mathematical expectation is denoted by symbol $E$.

Generally speaking, almost all sample trajectories of the process $\xi(t)$ are not differentiable, so that its derivatives exist only in the sense of generalized functions. To avoid using generalized functions according to Nelson [12-14], we give the following definition:

Definition 1. [15]

(i) The mean forward derivative $D \xi(t)$ of the process $\xi(t)$ at the time moment $t$ is an $L_{1}$-random element of the form

$$
D \xi(t)=\lim _{\triangle t \rightarrow+0} E_{t}^{\xi}\left(\frac{\xi(t+\triangle t)-\xi(t)}{\triangle t}\right)
$$

where the limit is assumed to exist in $L_{1}(\Omega, \mathcal{F}, \mathrm{P})$ and $\triangle t \rightarrow+0$ means that $\Delta t$ tends to 0 and $\triangle t>0$.

(ii) The mean backward derivative $D_{*} \xi(t)$ of the process $\xi(t)$ at time $t$ is $L_{1}$-random variable

$$
D_{*} \xi(t)=\lim _{\triangle t \rightarrow+0} E_{t}^{\xi}\left(\frac{\xi(t)-\xi(t-\triangle t)}{\triangle t}\right)
$$

where (as in (i)) the limit is assumed to exist in $L_{1}(\Omega, \mathcal{F}, \mathrm{P})$ and $\triangle t \rightarrow+0$ means that $\triangle t$ tends to 0 and $\triangle t>0$.

It should be noted that, in general, $D \xi(t) \neq D_{*} \xi(t)$, but if, for example, $\xi(t)$ almost surely has smooth sample trajectories, these derivatives obviously coincide. 
From the properties of conditional expectation (see [18]) it follows that $D \xi(t)$ and $D_{*} \xi(t)$ can be represented as superpositions of $\xi(t)$ and Borel vector fields (regressions)

$$
\begin{aligned}
& Y^{0}(t, x)=\lim _{\triangle t \rightarrow+0} E_{t}^{\xi}\left(\frac{\xi(t+\triangle t)-\xi(t)}{\triangle t} \mid \xi(t)=x\right) \\
& Y_{*}^{0}(t, x)=\lim _{\triangle t \rightarrow+0} E_{t}^{\xi}\left(\frac{\xi(t)-\xi(t-\triangle t)}{\triangle t} \mid \xi(t)=x\right)
\end{aligned}
$$

on $R^{n}$, that is, $D \xi(t)=Y^{0}(t, \xi(t))$ and $D_{*} \xi(t)=Y_{*}^{0}(t, \xi(t))$.

Definition 2. [15] The derivative $D_{S}=\frac{1}{2}\left(D+D_{*}\right)$ is called the symmetric derivative in the mean. The derivative $D_{A}=\frac{1}{2}\left(D-D_{*}\right)$ is called the antisymmetric derivative in the mean.

We consider the vector fields $v^{\xi}(t, x)=\frac{1}{2}\left(Y^{0}(t, x)+Y_{*}^{0}(t, x)\right)$ and $u^{\xi}(t, x)=\frac{1}{2}\left(Y^{0}(t, x)-\right.$ $\left.Y_{*}^{0}(t, x)\right)$.

Definition 3. [15] $v^{\xi}(t)=v^{\xi}(t, \xi(t))=D_{S} \xi(t)$ is called the current velocity of the process $\xi(t) ; u^{\xi}(t)=u^{\xi}(t, \xi(t))=D_{A} \xi(t)$ is called the osmotic velocity of the process $\xi(t)$.

The current velocity is a direct analogue of the ordinary physical velocity of deterministic processes for random processes (see [15]). The osmotic velocity measures how fast the "randomness" of the process grows.

We denote by the symbol $w(t)$ the Wiener process [15]. It plays a decisive role in our constructions. The following technical statements take place.

Lemma 1. [16] Let $w(t)$ be an $n$-dimensional Wiener process, $P(t)$ be a sufficiently smooth $k \times n$ matrix, $t \in(0, T)$. Then for any $t$ we have the formula

$$
D_{S}^{w} \int_{0}^{t} P(s) d w(s)=P(t) \frac{w(t)}{2 t} .
$$

Lemma 2. [15,17] For $t \in(0, T)$, the following equalities hold

$$
D w(t)=0, D_{*} w(t)=\frac{w(t)}{t}, D_{S} w(t)=\frac{w(t)}{2 t} .
$$

For the integer $k \geq 2$

$$
D_{S}^{k} w(t)=(-1)^{k-1} \frac{\prod_{i=1}^{k-1}(2 i-1)}{2^{k}} \frac{w(t)}{t^{k}}
$$

\section{Main Result}

As it is already mentioned in the introduction, we consider the stochastic differential equation in $R^{n}$ of the form

$$
\tilde{L} \xi(t)=\tilde{M} \int_{0}^{t} \xi(s) d s+\int_{0}^{t} f(s) d s+Q \zeta(t)+\int_{0}^{t} P(s) d w(s), 0 \leq t \leq T,
$$


where $\tilde{L}$ and $\tilde{M}$ are degenerate and nondegenerate $n \times n$ matrices, respectively, $\lambda \tilde{L}+\tilde{M}$, $\lambda \in R$ is a regular pencil of matrices, $Q$ is an $n \times n$ matrix, $\zeta(t)$ is an $n$-dimensional process of jumps, $P(t)$ is a sufficiently smooth $n \times n$ matrix, $f(t)$ is a sufficiently smooth time-dependent deterministic vector function, $w(t)$ is a Wiener process, $\xi(t)$ is the random process that we are looking for. The process of jumps $\zeta(t)=\zeta(t, \omega)$ is defined as follows

$$
\zeta(t, \omega)=\sum_{r=1}^{N} \tilde{\zeta}_{r}(\omega) \chi\left(t-t_{r}\right), 0<t_{1}<\cdots<t_{N}<T,
$$

where $\chi$ is the Heaviside function, which is zero for negative values of the argument and 1 for nonnegative, $\tilde{\zeta}_{r}(\omega)$ are random variables with values in $R^{n}$.

From the form of (1) it is clear that (for simplicity) the initial condition for the solution of (1) is assumed to be of the form

$$
\xi(0, \omega)=0
$$

From the very beginning we say that this condition is not satisfied for the solutions constructed below. Therefore, we approximate solutions by processes that satisfy this initial condition, but become solutions only from a certain (arbitrarily small) time instant $t_{0}>0$ (see below).

We seek the formulas for the solutions of the problem (1), (2) among random processes $\xi(t, \omega)$, which satisfy (in the sense, as described below) the differential equations

$$
\begin{gathered}
\tilde{L} \xi(t)-\tilde{L} \xi(0)=\tilde{M} \int_{0}^{t} \xi(s) d s+\int_{0}^{t} f(s) d s+\int_{0}^{t} P(s) d w(s), 0 \leq t \leq t_{1}, \\
\tilde{L} \xi(t)-\tilde{L} \xi\left(t_{r}\right)=\tilde{M} \int_{t_{r}}^{t} \xi(s) d s+\int_{t_{r}}^{t} f(s) d s+\int_{t_{r}}^{t} P(s) d w(s), t_{r} \leq t \leq t_{r+1}, \\
\tilde{L} \xi(t)-\tilde{L} \xi\left(t_{N}\right)=\tilde{M} \int_{t_{N}}^{t} \xi(s) d s+\int_{t_{N}}^{t} f(s) d s+\int_{t_{N}}^{t} P(s) d w(s), t_{N} \leq t \leq T,
\end{gathered}
$$

for all $r=1,2, \ldots, N-1$, at the points $t_{r}$ they satisfy the equalities

$$
\tilde{L} \xi\left(t_{r}+0, \omega\right)-\tilde{L} \xi\left(t_{r}-0, \omega\right)=Q \tilde{\zeta}_{r}(\omega), r=1,2, \ldots, N,
$$

and at the initial instant of time $t=0$ satisfy the initial condition (2).

Thus, the process $\xi(t)$ for the solution of the problem (1), (2) is determined sequentially for $r=0,1, \ldots, N$ through random processes $\xi_{r}(t)$, which satisfy the equations

$$
\begin{gathered}
\tilde{L} \xi_{0}(t)-\tilde{L} \xi_{0}(0)=\tilde{M} \int_{0}^{t} \xi_{0}(s) d s+\int_{0}^{t} f(s) d s+\int_{0}^{t} P(s) d w(s), 0 \leq t \leq t_{1}, \quad(r=0), \\
\tilde{L} \xi_{r}(t)-\tilde{L} \xi_{r}\left(t_{r}\right)=\tilde{M} \int_{t_{r}}^{t} \xi_{r}(s) d s+\int_{t_{r}}^{t} f(s) d s+\int_{t_{r}}^{t} P(s) d w(s), t_{r} \leq t \leq t_{r+1}, \\
\tilde{L} \xi_{N}(t)-\tilde{L} \xi_{N}\left(t_{N}\right)=\tilde{M} \int_{t_{N}}^{t} \xi_{N}(s) d s+\int_{t_{N}}^{t} f(s) d s+\int_{t_{N}}^{t} P(s) d w(s), t_{N} \leq t \leq T,
\end{gathered}
$$


$r=1,2, \ldots, N-1$, where

$$
\xi_{0}(0)=0, \tilde{L} \xi_{r}\left(t_{r}\right)=\tilde{L} \xi_{r-1}\left(t_{r}, \omega\right)+Q \tilde{\zeta}_{r}(\omega), \quad r=1, \ldots, N
$$

It is not hard to see, that equation (1) in a general form is inconvenient for studying, therefore we bring it to some canonical form. For a regular matrix pencil there exists a Kronecker-Weierstrass transformation (described by a pair of nondegenerate matrices (operators) $A=\left(a_{j}^{i}\right)$ and $\left.A_{R}\right)$ under which the matrices $\tilde{L}$ and $\tilde{M}$ are reduced to quasidiagonal form (see [19]), and, with the corresponding numbering of the basis vectors, in $L=A \tilde{L} A_{R}$ first along the main diagonal there are Jordan cells with zeros along the diagonal, and the last matrix along the main diagonal is the unit matrix. In $M=A \tilde{M} A_{R}$, in the rows corresponding to the Jordan blocks there is a unit matrix, and the last block along the main diagonal is a certain non-degenerate matrix. We give the matrices $L$ and $M$ in a general explicit form:

$$
\begin{aligned}
& L=\left(\begin{array}{cccccccccccc}
0 & 1 & 0 & 0 & 0 & 0 & \ldots & 0 & 0 & 0 & \ldots & 0 \\
0 & 0 & 1 & 0 & 0 & 0 & \ldots & 0 & 0 & 0 & \ldots & 0 \\
\vdots & \vdots & \vdots & \vdots & \vdots & \vdots & \vdots & \vdots & \vdots & \vdots & \vdots & \vdots \\
0 & 0 & 0 & 0 & 1 & 0 & \ldots & 0 & 0 & 0 & \ldots & 0 \\
0 & 0 & 0 & 0 & 0 & 0 & \ldots & 0 & 0 & 0 & \ldots & 0 \\
0 & 0 & 0 & 0 & 0 & 0 & \ldots & 1 & 0 & 0 & \ldots & 0 \\
0 & 0 & 0 & 0 & 0 & 0 & \ldots & 0 & 1 & 0 & \ldots & 0 \\
\vdots & \vdots & \vdots & \vdots & \vdots & \vdots & \vdots & \vdots & \vdots & \vdots & \vdots & \vdots \\
0 & 0 & 0 & 0 & 0 & 0 & \ldots & 0 & 0 & 0 & \ldots & 0 \\
0 & 0 & 0 & 0 & 0 & 0 & \ldots & 0 & 1 & 0 & \ldots & 0 \\
0 & 0 & 0 & 0 & 0 & 0 & \ldots & 0 & 0 & 1 & \ldots & 0 \\
\vdots & \vdots & \vdots & \vdots & \vdots & \vdots & \vdots & \vdots & \vdots & \vdots & \vdots & \vdots \\
0 & 0 & 0 & 0 & 0 & 0 & \ldots & 0 & 0 & 0 & \ldots & 1
\end{array}\right), \\
& M=\left(\begin{array}{cccccccccccc}
1 & 0 & 0 & 0 & 0 & 0 & 0 & 0 & 0 & 0 & \ldots & 0 \\
0 & 1 & 0 & 0 & 0 & 0 & 0 & 0 & 0 & 0 & \ldots & 0 \\
0 & 0 & 1 & 0 & 0 & 0 & 0 & 0 & 0 & 0 & \ldots & 0 \\
0 & 0 & 0 & 1 & 0 & 0 & 0 & 0 & 0 & 0 & \ldots & 0 \\
0 & 0 & 0 & 0 & 1 & 0 & 0 & 0 & 0 & 0 & \ldots & 0 \\
0 & 0 & 0 & 0 & 0 & 1 & 0 & 0 & 0 & 0 & \ldots & 0 \\
0 & 0 & 0 & 0 & 0 & 0 & 1 & 0 & 0 & 0 & \ldots & 0 \\
\vdots & \vdots & \vdots & \vdots & \vdots & \vdots & \vdots & \vdots & \vdots & \vdots & \vdots & \vdots \\
0 & 0 & 0 & 0 & 0 & 0 & 0 & 0 & a_{n-q}^{n-q} & a_{n-q}^{n-q+1} & \ldots & a_{n}^{n-q} \\
0 & 0 & 0 & 0 & 0 & 0 & 0 & 0 & a_{n-q}^{n-q+1} & a_{n-q+1}^{n-q+1} & \ldots & a_{n}^{n-q+1} \\
\vdots & \vdots & \vdots & \vdots & \vdots & \vdots & \vdots & \vdots & \vdots & \vdots & \vdots & \vdots \\
0 & 0 & 0 & 0 & 0 & 0 & 0 & 0 & a_{n-q}^{n} & a_{n-q+1}^{n} & \ldots & a_{n}^{n}
\end{array}\right) .
\end{aligned}
$$


Thus, after applying the Kronecker - Weierstrass transformation, equation (1) takes the following form

$$
\begin{gathered}
L \eta(t)=\int_{0}^{t} M \eta(s) d s+\int_{0}^{t} A f(s) d s+A Q \zeta(t)+\int_{0}^{t} B(s) d w(s), \\
\eta(0)=0,
\end{gathered}
$$

where $B(t)=A P(t), \eta(t)=A_{R}^{-1} \xi(t)$. Then, taking into account what has been said above, the formulas for the solutions $\eta(t)$ of problem (3), (4) are determined successively for $r=0,1, \ldots, N$ through random processes $\eta_{r}(t)$, which satisfy the equations

$$
\begin{aligned}
L \eta_{0}(t)-L \eta_{0}(0) & =\int_{0}^{t} M \eta_{0}(s) d s+\int_{0}^{t} A f(s) d s+\int_{0}^{t} B(s) d w(s), 0 \leq t \leq t_{1}, \\
L \eta_{r}(t)-L \eta_{r}\left(t_{r}\right) & =\int_{t_{r}}^{t} M \eta_{r}(s) d s+\int_{t_{r}}^{t} A f(s) d s+\int_{t_{r}}^{t} B(s) d w(s), t_{r} \leq t \leq t_{r+1}, \\
L \eta_{N}(t)-L \eta_{N}\left(t_{N}\right) & =\int_{t_{N}}^{t} M \eta_{N}(s) d s+\int_{t_{N}}^{t} A f(s) d s+\int_{t_{N}}^{t} B(s) d w(s), t_{N} \leq t \leq T,
\end{aligned}
$$

$r=1, \ldots, N-1$, where

$$
\eta_{0}(0)=0, L \eta_{r}\left(t_{r}\right)=L \eta_{r-1}\left(t_{r}, \omega\right)+G \tilde{\zeta}_{r}(\omega), r=1, \ldots, N
$$

and $G=A Q$.

Remark 1. As it is noted above, derivatives of free terms (including the Wiener process) are needed to construct the process describing the model given by equations (5), (6) and (7). The derivatives of the Wiener process exist only in the sense of generalized functions. Therefore, in order to avoid the use of generalized functions, we use the symmetric mean derivatives (current velocities) $D_{S}^{w}$ of the Wiener process to describe the model given by $(5),(6)$ and $(7)$ processes. In this paper, the $\sigma$-algebra "present" of the Wiener process will be used to calculate higher-order symmetric mean derivatives. Note that to calculate the mean derivatives, one can also use some other $\sigma$-algebra, but then the formulas for computing higher-order symmetric derivatives of the Wiener process will be changed.

Taking into account the structure of matrices $L$ and $M$, it is not difficult to see that problems (3), (4) and (5) - (8) break up into several independent systems of equations. The "bottom" of them corresponds to the unit segment in the diagonal in $L$ and the block consisting of a matrix in the lower right corner of $M$. Denote the last matrix by $K$, and denote by $\vartheta(t)$ the vector of dimension $q+1$, composed of the last $q+1$ coordinates of the vector $\eta(t)$. Then $\vartheta_{r}(t)$ is described by the equation

$$
\begin{gathered}
\vartheta_{r}(t)-\vartheta_{r}\left(t_{r}\right)=K \int_{t_{r}}^{t} \vartheta_{r}(s) d s+\int_{t_{r}}^{t} A f(s) d s+\int_{t_{r}}^{t} B_{(q+1)}(s) d w(s), \\
t_{r} \leq t \leq t_{r+1}, r=1,2, \ldots, N-1
\end{gathered}
$$


in $R^{q+1}$. Here $B_{(q+1)}(t)$ is the matrix composed of the last $q+1$ rows of the matrix $B(t)$, $w(t)$ is $(q+1)$-dimensional Wiener process composed of the last $q+1$ coordinates of the Wiener process in $R^{n}, A f(t)$ is $(q+1)$-dimensional vector composed of the last $q+1$ coordinates of the vector $A f(t)$. For equation (9), the analytic formula for solutions is known (see [20]):

$$
\vartheta_{r}(t)=e^{K\left(t-t_{r}\right)} \vartheta_{r}\left(t_{r}\right)+\int_{t_{r}}^{t} e^{K(t-\tau)} A f(\tau) d \tau+\int_{t_{r}}^{t} e^{K(t-\tau)} B_{(q+1)}(\tau) d w(\tau) .
$$

Note that for equations of the form (9) defined on the intervals $\left[0, t_{1}\right]$ and $\left[t_{N}, T\right]$, analogous formulas hold for solutions. Summing all $\vartheta_{r}(t)$, we obtain the expression for $\vartheta(t)$

$$
\begin{gathered}
\vartheta(t)=\sum_{r=1}^{N} e^{K\left(t-t_{r}\right)} G \tilde{\zeta}_{r}(\omega) \chi\left(t-t_{r}\right)+ \\
+\int_{0}^{t} e^{K(t-\tau)} A f(\tau) d \tau+\int_{0}^{t} e^{K(t-\tau)} B_{(q+1)}(\tau) d w(\tau),
\end{gathered}
$$

where $G \tilde{\zeta}_{r}(\omega)$ is $(q+1)$-dimensional vector composed from the last $q+1$ coordinates of the vector $G \tilde{\zeta}_{r}(\omega)$.

The other systems correspond to Jordan cells in $L$ and unit matrices of the corresponding dimension chosen from the rows and columns of $M$. We consider this case by the example of the $(p+1) \times(p+1)$ matrix (the Jordan cell) $N$ in the upper left corner of $L$

$$
N=\left(\begin{array}{ccccc}
0 & 1 & 0 & \ldots & 0 \\
0 & 0 & 1 & \ldots & 0 \\
\vdots & \vdots & \vdots & \ldots & \vdots \\
0 & 0 & 0 & \ldots & 1 \\
0 & 0 & 0 & \ldots & 0
\end{array}\right)
$$

and the corresponding identity matrix in $M$. We denote by $(A f)_{p+1}$ the $(p+1)$-dimensional vector composed of the first $p+1$ coordinates of the vector $A f(t)$, by $\eta_{(p+1)}(t)-$ the $(p+1)$-dimensional vector composed from the first $p+1$ coordinates of the vector $\eta(t)$, and $w_{(p+1)}(t)$ is the vector consisting of the first $p+1$ coordinates of the vector $w(t)$. It is easy to see that the coordinates of the vector $A f$ have the form $(A f)^{i}=\sum_{j=1}^{n} a_{j}^{i} f^{j}$. We denote by $B_{(p+1)}(t)$ the matrix

$$
B_{(p+1)}(t)=\left(\begin{array}{ccccc}
b_{1}^{1}(t) & b_{2}^{1}(t) & \ldots & b_{n-1}^{1}(t) & b_{n}^{1}(t) \\
b_{1}^{2}(t) & b_{2}^{2}(t) & \ldots & b_{n-1}^{2}(t) & b_{n}^{2}(t) \\
\vdots & \vdots & \ldots & \vdots & \vdots \\
b_{1}^{p}(t) & b_{2}^{p}(t) & \ldots & b_{n-1}^{p}(t) & b_{n}^{p}(t) \\
b_{1}^{p+1}(t) & b_{2}^{p+1}(t) & \ldots & b_{n-1}^{p+1}(t) & b_{n}^{p+1}(t)
\end{array}\right)
$$

composed of the first $p+1$ rows of the matrix $B(t)$. 
Then $\left(\eta_{r}\right)_{(p+1)}(t)$ is a solution of equation

$$
\begin{gathered}
N\left(\eta_{r}\right)_{(p+1)}(t)-N\left(\eta_{r}\right)_{(p+1)}\left(t_{r}\right)=\int_{t_{r}}^{t}\left(\left(\eta_{r}\right)_{(p+1)}(s)+(A f)_{(p+1)}(s)\right) d s+ \\
+\int_{t_{r}}^{t} B_{(p+1)}(s) d w(s), \\
t_{r} \leq t \leq t_{r+1}, r=1,2, \ldots, N-1 .
\end{gathered}
$$

In the coordinate form, this equation looks as follows:

$$
\begin{aligned}
& \left(\begin{array}{ccccc}
0 & 1 & 0 & \ldots & 0 \\
0 & 0 & 1 & \ldots & 0 \\
\vdots & \vdots & \vdots & \ldots & \vdots \\
0 & 0 & 0 & \ldots & 1 \\
0 & 0 & 0 & \ldots & 0
\end{array}\right)\left(\begin{array}{c}
\eta_{r}^{1}(t) \\
\eta_{r}^{2}(t) \\
\vdots \\
\eta_{r}^{p}(t) \\
\eta_{r}^{p+1}(t)
\end{array}\right)-\left(\begin{array}{ccccc}
0 & 1 & 0 & \ldots & 0 \\
0 & 0 & 1 & \ldots & 0 \\
\vdots & \vdots & \vdots & \ldots & \vdots \\
0 & 0 & 0 & \ldots & 1 \\
0 & 0 & 0 & \ldots & 0
\end{array}\right)\left(\begin{array}{c}
\eta_{r}^{1}\left(t_{r}\right) \\
\eta_{r}^{2}\left(t_{r}\right) \\
\vdots \\
\eta_{r}^{p}\left(t_{r}\right) \\
\eta_{r}^{p+1}\left(t_{r}\right)
\end{array}\right)= \\
& =\left(\begin{array}{c}
\int_{t_{r}}^{t}\left(\eta_{r}^{1}(s)+\sum_{j=1}^{n} a_{j}^{1} f^{j}\right) d s \\
\int_{t_{r}}^{t}\left(\eta_{r}^{2}(s)+\sum_{j=1}^{n} a_{j}^{2} f^{j}\right) d s \\
\vdots \\
\int_{t_{r}}^{t}\left(\eta_{r}^{p}(s)+\sum_{j=1}^{n} a_{j}^{p} f^{j}\right) d s \\
\int_{t_{r}}^{t}\left(\eta_{r}^{p+1}(s)+\sum_{j=1}^{n} a_{j}^{p+1} f^{j}\right) d s
\end{array}\right)+ \\
& +\int_{t_{r}}^{t}\left(\begin{array}{ccccc}
b_{1}^{1}(s) & b_{2}^{1}(s) & \ldots & b_{n-1}^{1}(s) & b_{n}^{1}(s) \\
b_{1}^{2}(s) & b_{2}^{2}(s) & \ldots & b_{n-1}^{2}(s) & b_{n}^{2}(s) \\
\vdots & \vdots & \ldots & \vdots & \vdots \\
b_{1}^{p}(s) & b_{2}^{p}(s) & \ldots & b_{n-1}^{p}(s) & b_{n}^{p}(s) \\
b_{1}^{p+1}(s) & b_{2}^{p+1}(s) & \ldots & b_{n-1}^{p+1}(s) & b_{n}^{p+1}(s)
\end{array}\right) d\left(\begin{array}{c}
w^{1}(s) \\
w^{2}(s) \\
\vdots \\
w^{n-1}(s) \\
w^{n}(s)
\end{array}\right)
\end{aligned}
$$

where $r=1,2, \ldots, N-1$. From the last equation of (11) we obtain that

$$
\int_{t_{r}}^{t} \eta_{r}^{p+1}(s) d s=-\int_{t_{r}}^{t} \sum_{j=1}^{n} a_{j}^{p+1} f^{j} d s-\sum_{j=1}^{n} \int_{t_{r}}^{t} b_{j}^{p+1}(s) d w^{j}(s) .
$$

Since the current velocity (the symmetric mean derivative) corresponds to the physical velocity, from this equation we find $\eta_{r}^{p+1}(t)$ by applying the derivative $D_{S}^{w}$ to both parts of the equality (see Remark 1). It is easy to see that the application of mean derivatives $D^{w}$ and $D_{*}^{w}$ (and, consequently, $D_{S}^{w}$ ) to the Riemann integrals on the left and right sides yields the same results $\eta_{r}^{p+1}(t)$ and $\left.\sum_{j=1}^{n} a_{j}^{p+1} f^{j}\right)$. Thus, using Lemma 1, we obtain that

$$
\eta_{r}^{p+1}(t)=-\sum_{j=1}^{n} a_{j}^{p+1} f^{j}-\sum_{l=1}^{n} b_{l}^{p+1} \frac{w^{l}(t)}{2 t}
$$


$r=1,2, \ldots, N-1$. From the penultimate equation of system (11) we obtain that

$$
\eta_{r}^{p+1}(t)-\eta_{r}^{p+1}\left(t_{r}\right)=\int_{t_{r}}^{t}\left(\eta_{r}^{p}(s)+\sum_{j=1}^{n} a_{j}^{p} f^{j}\right) d s+\sum_{l=1}^{n} \int_{t_{r}}^{t} b_{l}^{p} d w^{l}(s),
$$

whence, after a reasoning analogous to what is done above, using Lemma 2, we deduce

$$
\eta_{r}^{p}=-\sum_{j=1}^{n} a_{j}^{p+1} \frac{d f^{j}}{d t}-\sum_{l=1}^{n} D_{S}\left(b_{l}^{p+1} \frac{w^{l}}{2 t}\right)-\sum_{j=1}^{n} a_{j}^{p} f^{j}-\sum_{l=1}^{n} b_{l}^{p} \frac{w^{l}}{2 t},
$$

that is identical to

$$
\eta_{r}^{p}=-\sum_{j=1}^{n} a_{j}^{p+1} \frac{d f^{j}}{d t}-\sum_{j=1}^{n} a_{j}^{p} f^{j}-\sum_{l=1}^{n} \frac{d b_{l}^{p+1}}{d t} \frac{w^{l}}{2 t}+\sum_{l=1}^{n} b_{l}^{p+1} \frac{w^{l}}{4 t^{2}}-\sum_{l=1}^{n} b_{l}^{p} \frac{w^{l}}{2 t} .
$$

Also for the third equation "from below" of system (11)

$$
\eta_{r}^{p}-\eta_{r}^{p}\left(t_{r}\right)=\int_{t_{r}}^{t}\left(\eta^{p-1}+\sum_{j=1}^{n} a_{j}^{p-1} f^{j}\right) d s+\sum_{l=1}^{n} \int_{t_{r}}^{t} b_{l}^{p-1} d w^{l}(s)
$$

we have

$$
\begin{gathered}
\eta_{r}^{p-1}=-\sum_{j=1}^{n} a_{j}^{p+1} \frac{d^{2} f^{j}}{d t^{2}}-\sum_{j=1}^{n} a_{j}^{p} \frac{d f^{j}}{d t}-\sum_{j=1}^{n} a_{j}^{p-1} f^{j}-\sum_{l=1}^{n} D_{S}^{2}\left(b_{l}^{p+1} \frac{w^{l}}{2 t}\right)- \\
-\sum_{l=1}^{n} D_{S}\left(b_{l}^{p} \frac{w^{l}}{2 t}\right)-\sum_{l=1}^{n} b_{l}^{p-1} \frac{w^{l}}{2 t}
\end{gathered}
$$

which is identical to

$$
\begin{aligned}
\eta_{r}^{p-1} & =-\sum_{j=1}^{n} a_{j}^{p+1} \frac{d^{2} f^{j}}{d t^{2}}-\sum_{j=1}^{n} a_{j}^{p} \frac{d f^{j}}{d t}-\sum_{j=1}^{n} a_{j}^{p-1} f^{j}- \\
-\sum_{l=1}^{n} & \frac{d^{2} b_{l}^{p+1}}{d t^{2}} \frac{w^{l}}{2 t}+2 \sum_{l=1}^{n} \frac{d b_{l}^{p+1}}{d t} \frac{w^{l}}{4 t^{2}}-\sum_{l=1}^{n} b_{l}^{p+1} \frac{3 w^{l}}{8 t^{3}}- \\
& -\sum_{l=1}^{n} \frac{d b_{l}^{p}}{d t} \frac{w^{l}}{2 t}+\sum_{l=1}^{n} b_{l}^{p} \frac{w^{l}}{4 t^{2}}-\sum_{l=1}^{n} b_{l}^{p-1} \frac{w^{l}}{2 t} .
\end{aligned}
$$

In exactly the same way, for $1 \leq i \leq p$ we obtain the recursion formula

$$
\begin{gathered}
\eta_{r}^{i}(t)=D_{S}^{w} \eta_{k}^{i+1}(t)-D_{S}^{w}\left\{\int_{t_{r}}^{t} b_{1}^{i}(s) d w^{1}(s)+\right. \\
\left.+\int_{t_{r}}^{t} b_{2}^{i}(s) d w^{2}(s)+\ldots+\int_{t_{r}}^{t} b_{n}^{i}(s) d w^{n}(s)\right\}-\sum_{j=1}^{n} a_{j}^{i} f^{j} .
\end{gathered}
$$


By the method of mathematical induction, we obtain the expression for any $\eta^{i}(t)$

$$
\begin{gathered}
\eta_{r}^{i}=-\sum_{j=1}^{n} a_{j}^{p+1} \frac{d^{p+1-i} f^{j}}{d t^{p+1-i}}-\sum_{j=1}^{n} a_{j}^{p} \frac{d^{p-i} f^{j}}{d t^{p-i}}- \\
-\sum_{j=1}^{n} a_{j}^{p-1} \frac{d^{p-i-1} f^{j}}{d t^{p-i-1}}-\ldots-\sum_{j=1}^{n} a_{j}^{i} f^{j}-\sum_{l=1}^{n} D_{S}^{p+1-i}\left(b_{l}^{p+1} \frac{w^{l}}{2 t}\right)-\sum_{l=1}^{n} D_{S}^{p-i}\left(b_{l}^{p} \frac{w^{l}}{2 t}\right)- \\
-\sum_{l=1}^{n} D_{S}^{p-i-1}\left(b_{l}^{p-1} \frac{w^{l}}{2 t}\right)-\ldots-\sum_{l=1}^{n} b_{l}^{i} \frac{w^{l}}{2 t}, 1 \leq i \leq p,
\end{gathered}
$$

that is identical to

$$
\begin{aligned}
\eta_{r}^{i} & =-\sum_{k=i}^{p} \sum_{j=1}^{n} a_{j}^{k+1} \frac{d^{k-i+1} f^{j}}{d t^{k-i+1}}-\sum_{j=1}^{n} a_{j}^{i} f^{j}-\sum_{l=1}^{n} D_{S}\left(b_{l}^{i+1} \frac{w^{l}}{2 t}\right)- \\
& -\sum_{m=i+1}^{p} \sum_{l=1}^{n} D_{S}^{m-i+1}\left(b_{l}^{m+1} \frac{w^{l}}{2 t}\right)-\sum_{l=1}^{n} b_{l}^{i} \frac{w^{l}}{2 t}, 1 \leq i \leq p-1 .
\end{aligned}
$$

According to the Leibniz formula for differentiating the product, we obtain

$$
\begin{gathered}
D_{S}^{m-i+1}\left(b_{l}^{m+1} \frac{w^{l}}{2 t}\right)=\frac{d^{m-i+1} b_{l}^{m+1}}{d t^{m-i+1}} \frac{w^{l}}{2 t}+b_{l}^{m+1} D_{S}^{m-i+1} \frac{w^{l}}{2 t}+ \\
+\sum_{k=1}^{m-i} C_{m-i+1}^{k} \frac{d^{m-i+1-k} b_{l}^{m+1}}{d t^{m-i+1-k}} D_{S}^{k} \frac{w^{l}}{2 t} \\
1 \leq i \leq p-1, i+1 \leq m \leq p, C_{n_{1}}^{k_{1}}=\frac{n_{1} !}{k_{1} !\left(n_{1}-k_{1}\right) !}
\end{gathered}
$$

and

$$
\sum_{l=1}^{n} D_{S}\left(b_{l}^{i+1} \frac{w^{l}}{2 t}\right)=\sum_{l=1}^{n} \frac{d b_{l}^{i+1}}{d t} \frac{w^{l}}{2 t}-\sum_{l=1}^{n} b_{l}^{i+1} \frac{w^{l}}{4 t^{2}}
$$

Consequently,

$$
\begin{gathered}
\eta_{r}^{i}=-\sum_{k=i}^{p} \sum_{j=1}^{n} a_{j}^{k+1} \frac{d^{k-i+1} f^{j}}{d t^{k-i+1}}-\sum_{j=1}^{n} a_{j}^{i} f^{j}-\sum_{l=1}^{n} \frac{d b_{l}^{i+1}}{d t} \frac{w^{l}}{2 t}+ \\
+\sum_{l=1}^{n} b_{l}^{i+1} \frac{w^{l}}{4 t^{2}}-\sum_{m=i+1}^{p} \sum_{l=1}^{n}\left\{\frac{d^{m-i+1} b_{l}^{m+1}}{d t^{m-i+1}} \frac{w^{l}}{2 t}+b_{l}^{m+1} D_{S}^{m-i+1} \frac{w^{l}}{2 t}+\right. \\
\left.+\sum_{k=1}^{m-i} C_{m-i+1}^{k} \frac{d^{m-i+1-k} b_{l}^{m+1}}{d t^{m-i+1-k}} D_{S}^{k} \frac{w^{l}}{2 t}\right\}-\sum_{l=1}^{n} b_{l}^{i} \frac{w^{l}}{2 t}, 1 \leq i \leq p-1 .
\end{gathered}
$$


Taking into account Lemma 2, we obtain the explicit expression for any $\eta_{r}^{i}(t)$

$$
\begin{gathered}
\eta_{r}^{i}=-\sum_{k=i}^{p} \sum_{j=1}^{n} a_{j}^{k+1} \frac{d^{k-i+1} f^{j}}{d t^{k-i+1}}-\sum_{j=1}^{n} a_{j}^{i} f^{j}-\sum_{l=1}^{n} \frac{d b_{l}^{i+1}}{d t} \frac{w^{l}}{2 t}+ \\
+\sum_{l=1}^{n} b_{l}^{i+1} \frac{w^{l}}{4 t^{2}}-\sum_{m=i+1}^{p} \sum_{l=1}^{n}\left\{\frac{d^{m-i+1} b_{l}^{m+1}}{d t^{m-i+1}} \frac{w^{l}}{2 t}+\right. \\
+b_{l}^{m+1}(-1)^{m-i+1} \frac{\prod_{j=1}^{m-i+1}(2 j-1)}{2^{m-i+2}} \frac{w^{l}(t)}{t^{m-i+2}}+ \\
\left.+\sum_{k=1}^{m-i} C_{m-i+1}^{k} \frac{d^{m-i+1-k} b_{l}^{m+1}}{d t^{m-i+1-k}}(-1)^{k} \frac{\prod_{j=1}^{k}(2 j-1)}{2^{k+1}} \frac{w^{l}(t)}{t^{k+1}}\right\}-\sum_{l=1}^{n} b_{l}^{i} \frac{w^{l}}{2 t}, \\
1 \leq i \leq p-1 .
\end{gathered}
$$

We note that for equations of the form (10), defined on the intervals $\left[0, t_{1}\right]$ and $\left[t_{N}, T\right]$, analogous formulas for solutions take place for $0<t \leq t_{1}$ and $t_{N} \leq t<T$ respectively. In this case, the processes found above, satisfy conditions (8) when the components of the random variable $G \tilde{\zeta}_{r}(\omega)$ corresponding to Jordan cells with zeros along the main diagonal in $L$ are equal to zero.

Thus, taking into account what has been said above, for $0<t<T$ we obtain formulas for $\eta_{(p+1)}(t)$ :

$$
\begin{gathered}
\eta^{p+1}=-\sum_{j=1}^{n} a_{j}^{p+1} f^{j}-\sum_{l=1}^{n} b_{l}^{p+1} \frac{w^{l}(t)}{2 t} \\
\eta^{p}=-\sum_{j=1}^{n} a_{j}^{p+1} \frac{d f^{j}}{d t}-\sum_{j=1}^{n} a_{j}^{p} f^{j}-\sum_{l=1}^{n} \frac{d b_{l}^{p+1}}{d t} \frac{w^{l}}{2 t}+\sum_{l=1}^{n} b_{l}^{p+1} \frac{w^{l}}{4 t^{2}}-\sum_{l=1}^{n} b_{l}^{p} \frac{w^{l}}{2 t} \\
\eta^{i}=-\sum_{k=i}^{p} \sum_{j=1}^{n} a_{j}^{k+1} \frac{d^{k-i+1} f^{j}}{d t^{k-i+1}}-\sum_{j=1}^{n} a_{j}^{i} f^{j}-\sum_{l=1}^{n} \frac{d b_{l}^{i+1}}{d t} \frac{w^{l}}{2 t}+ \\
+\sum_{l=1}^{n} b_{l}^{i+1} \frac{w^{l}}{4 t^{2}}-\sum_{m=i+1}^{p} \sum_{l=1}^{n}\left\{\frac{d^{m-i+1} b_{l}^{m+1}}{d t^{m-i+1}} \frac{w^{l}}{2 t}+\right. \\
+b_{l}^{m+1}(-1)^{m-i+1} \frac{\prod_{j=1}^{m}(2 j-1)}{2^{m-i+2}} \frac{w^{l}(t)}{t^{m-i+2}}+ \\
\left.+\sum_{k=1}^{m-i} C_{m-i+1}^{k} \frac{d^{m-i+1-k} b_{l}^{m+1}}{d t^{m-i+1-k}}(-1)^{k} \frac{\prod_{j=1}^{k}(2 j-1)}{2^{k+1}} \frac{w^{l}(t)}{t^{k+1}}\right\}-\sum_{l=1}^{n} b_{l}^{i} \frac{w^{l}}{2 t} \\
1 \leq i \leq p-1 .
\end{gathered}
$$

Now we turn to the question of zero initial conditions for the solutions of system (11) (for $r=0$ ). Taking into account the definition of symmetric mean derivatives, it is not difficult to see that they are well-posed only on open intervals of time, since in their construction both time increments to the right and to the left are used. Formulas (12) (14) and (15) show that the solutions $\eta^{l}(t)$ are described as the sums in which each term contains the factor of the form $\frac{w^{j}(t)}{t^{k}}, k \geq 1$. Consequently, the solutions tend to infinity 
as $t \rightarrow 0$; the values of the solutions for $t=0$ do not exist. One idea to improve this situation (as in [17]) is as follows. We fix an arbitrarily small time instant $t_{0} \in(0, T)$ and define the function $t_{0}(t)$ by the formula

$$
t_{0}(t)=\left\{\begin{array}{l}
t_{0}, \text { if } 0 \leq t \leq t_{0} \\
t, \text { if } t_{0} \leq t
\end{array}\right.
$$

The elements $\frac{w^{j}(t)}{t^{k}}$ in the formulas $(12)-(14)$ and (15) are replaced by $\frac{w^{j}(t)}{\left(t_{0}(t)\right)^{k}}$. The resulting processes at time $t=0$ will assume zero values, but they will become solutions only for $t_{0} \leq t<T$. Note that for two different time instants, $t_{0}^{(1)}$ and $t_{0}^{(2)}$ for $t \geq$ $\max \left(t_{0}^{(1)}, t_{0}^{(2)}\right)$ the values of the corresponding processes coincide.

Thus, summing up what has been said above, we have proved the following statement.

Theorem 1. Let $\lambda \tilde{L}+\tilde{M}$ be a regular pencil of $n \times n$ matrices, $Q$ is an $n \times n$ matrix, and $f(t)$ is a sufficiently smooth $n$-dimensional vector-valued function, $0 \leq t \leq T$; let $0<t_{1}<\cdots<t_{N}<T ; A$ and $A_{R}$ are nondegenerate matrices of size $n \times n$ that reduce the pencil $\lambda \tilde{L}+\tilde{M}$ to the canonical Kronecker - Weierstrass form (that is, to the quasidiagonal form ), $L=A \tilde{L} A_{R}$ and $M=A \tilde{M} A_{R}, G=A Q ;$ let $\tilde{\zeta}_{r}(\omega), r=1,2, \ldots, N$ be random variables with values in $R^{n}$ such that the components of the random variable $G \tilde{\zeta}_{r}(\omega)$ corresponding to Jordan cells with zeros along the main diagonal in $L$ are equal to zero; let $\zeta(t, \omega)=\sum_{r=1}^{N} \tilde{\zeta}_{r}(\omega) \chi\left(t-t_{r}\right)$, where $\chi$ is the Heaviside function, equal to zero for negative values of the argument and 1 for non-negative ones. Then:

1) equation (1) is transformed into the canonical equation (3), which splits into independent subsystems of the equations;

2) for the subsystem in $R^{q+1}$ corresponding to the identity matrix in $L$ and the nondegenerate $(q+1) \times(q+1)$ matrix $K$ in $M$ the following analytic formula for solutions of the form

$$
\vartheta(t)=\sum_{r=1}^{N} e^{K\left(t-t_{r}\right)} G \tilde{\zeta}_{r}(\omega) \chi\left(t-t_{r}\right)+\int_{0}^{t} e^{K(t-\tau)} A f(\tau) d \tau+\int_{0}^{t} e^{K(t-\tau)} B_{(q+1)}(\tau) d w(\tau),
$$

takes place where $G \tilde{\zeta}_{r}(\omega), A f(t)$ are the corresponding components of the vectors $\left.G \tilde{\zeta}_{r}(\omega)\right)$, Af $(t)$, belonging to $R^{q+1}$;

3) for the subsystems corresponding to Jordan blocks in L of size $(p+1) \times(p+1)$ with zeros along the main diagonal and unit matrices in $M$, for $0<t<T$ we have formulas for solutions of the form

$$
\begin{gathered}
\eta^{p+1}=-\sum_{j=1}^{n} a_{j}^{p+1} f^{j}-\sum_{l=1}^{n} b_{l}^{p+1} \frac{w^{l}(t)}{2 t} \\
\eta^{p}=-\sum_{j=1}^{n} a_{j}^{p+1} \frac{d f^{j}}{d t}-\sum_{j=1}^{n} a_{j}^{p} f^{j}-\sum_{l=1}^{n} \frac{d b_{l}^{p+1}}{d t} \frac{w^{l}}{2 t}+\sum_{l=1}^{n} b_{l}^{p+1} \frac{w^{l}}{4 t^{2}}-\sum_{l=1}^{n} b_{l}^{p} \frac{w^{l}}{2 t}, \\
\eta^{i}=-\sum_{k=i}^{p} \sum_{j=1}^{n} a_{j}^{k+1} \frac{d^{k-i+1} f^{j}}{d t^{k-i+1}}-\sum_{j=1}^{n} a_{j}^{i} f^{j}-\sum_{l=1}^{n} \frac{d b_{l}^{i+1}}{d t} \frac{w^{l}}{2 t}+\sum_{l=1}^{n} b_{l}^{i+1} \frac{w^{l}}{4 t^{2}}-
\end{gathered}
$$

Вестник ЮУрГУ. Серия «Математическое моделирование 


$$
\begin{gathered}
-\sum_{m=i+1}^{p} \sum_{l=1}^{n}\left\{\frac{d^{m-i+1} b_{l}^{m+1}}{d t^{m-i+1}} \frac{w^{l}}{2 t}+b_{l}^{m+1}(-1)^{m-i+1} \frac{\prod_{j=1}^{m-i+1}(2 j-1)}{2^{m-i+2}} \frac{w^{l}(t)}{t^{m-i+2}}+\right. \\
\left.+\sum_{k=1}^{m-i} C_{m-i+1}^{k} \frac{d^{m-i+1-k} b_{l}^{m+1}}{d t^{m-i+1-k}}(-1)^{k} \frac{\prod_{j=1}^{k}(2 j-1)}{2^{k+1}} \frac{w^{l}(t)}{t^{k+1}}\right\}-\sum_{l=1}^{n} b_{l}^{i} \frac{w^{l}}{2 t}, 1 \leq i \leq p-1 ;
\end{gathered}
$$

4) fixing an arbitrarily small time instant $t_{0}>0$, we replace the $t$ by $t_{0}(t)$ in the denominators of the processes given in step 3) by formula (16) and obtain processes that take at $t=0$ zero values, but they are solutions only for $t_{0} \leq t<T$.

Acknowledgment. The research is supported in part by RFBR Grant 18-01-00048.

\section{References}

1. Shestakov A.L., Sviridyuk G.A. A New Approach to the Measurement of Dynamically Distorted Signals. Bulletin of South Ural State University. Series: Mathematical Modelling, Programming and Computer Software, 2010, no. 16 (192), issue 5, pp. 116-120.

2. Shestakov A.L., Keller A.V., Sviridyuk G.A. The Theory of Optimal Measurements. Journal of Computational and Engineering Mathematics, 2014, vol. 1, no. 1, pp. 3-16.

3. Shestakov A.L., Sviridyuk G.A. On the Measurement of the "White Noise". Bulletin of South Ural State University. Series: Mathematical Modelling, Programming and Computer Software, 2012, no. 27 (286), issue 13, pp. 99-108.

4. Schein O., Denk G. Numerical Solution of Stochastic Differential-Algebraic Equations with Applications to Transient Noise Simulation of Microelectronic Circuits. Journal of Computational and Applied Mathematics, 1998, vol. 100, no. 1, pp. 77-92. DOI: $10.1016 /$ S0377-0427(98)00138-1

5. Sickenberger T., Winkler R. Stochastic Oscillations in Circuit Simulation. Proceeding in Applied Mathematics and Mechanics, 2007, vol. 7, no. 1, pp. 4050023-4050024. DOI: $10.1002 /$ pamm. 200700807

6. Winkler R. Stochastic DAEs in Transient Noise Simulation. Proceedings of Scientific Computing in Electrical Engineering, 2004, vol. 4, pp. 408-415. DOI: 10.1007/978-3-64255872-6_45

7. Vlasenko L.A., Lysenko Yu.G., Rutkas A.G. About One Stochastic Model of Enterprise Corporations Dynamics. Economic Cybernetics, 2011, no. 1-3 (67-69), pp. 4-9.

8. Vlasenko L.A., Lyshko S.L., Rutkas A.G. On a Stochastic Impulsive System. Reports of the National Academy of Sciences of Ukraine, 2012, no. 2, pp. 50-55.

9. Belov A.A., Kurdyukov A.P. [Descriptor Systems and Control Problems]. Moscow, Fizmatlit, 2015. (in Russian)

10. Mashkov E.Yu. Stochastic Equations of Leontief Type with Time-Dependent Diffusion Coefficient. Bulletin of Voronezh State University. Series: Physics. Mathematics, 2017, no. 3, pp. $148-158$.

11. Mashkov E.Yu. Singular Stochastic Leontieff Type Equation with Dependency on Time Diffusion Coefficients. Global and Stochastic Analysis, 2017, vol. 4, no. 2, pp. 207-217.

12. Nelson E. Derivation of the Schrödinger Equation from Newtonian Mechanics. Physics Reviews, 1966, vol. 150, no. 4, pp. 1079-1085. DOI: 10.1103/PhysRev.150.1079 
13. Nelson E. Dynamical Theory of Brownian Motion. Princeton, Princeton University Press, 1967.

14. Nelson E. Quantum Fluctuations. Princeton, Princeton University Press, 1985.

15. Gliklikh Yu.E. Global and Stochastic Analysis in Mathematical Problems Physics. Moscow, Comkniga, 2005.

16. Gliklikh Yu.E., Mashkov E.Yu. Stochastic Leontieff Type Equation with Non-Constant Coefficients. Applicable Analysis: An International Journal, 2015, vol. 94, no. 8, pp. 1614-1623. DOI: 10.1080/00036811.2014.940521

17. Gliklikh Yu.E., Mashkov E.Yu. Stochastic Leontief Type Equations and Derivatives in the Mean of Stochastic Processes. Bulletin of South Ural State University. Series: Mathematical Modelling, Programming and Computer Software, 2013, vol. 6, no. 2, pp.25-39.

18. Partasarati K.R. Introduction to Probability Theory and Measure Theory. Moscow, Mir, 1988.

19. Gantmakher F.R. The Matrix Theory. Moscow, Fizmatlit, 1967.

20. Gihman I.I., Scorohod A.V. Theory of Stochastic Processes, N.Y., Springer, 1979.

Received March 8, 2018

УДК $517.9+519.216 .2$

DOI: $10.14529 / \mathbf{m m p} 180205$

\section{СТОХАСТИЧЕСКИЕ УРАВНЕНИЯ ЛЕОНТЬЕВСКОГО ТИПА С ИМПУЛЬСНЫМИ ВОЗДЕЙСТВИЯМИ}

E.Ю. Машков, Юго-Западный государственный университет, г. Курск, Российская Федерация

Под стохастическим уравнением леонтьевского типа понимается специальный класс стохастических дифференциальных уравнений в форме Ито, у которых в левой части имеется вырожденный постоянный линейный оператор, а в правой части невырожденный постоянный линейный оператор. Кроме этого, в правой части имеется детерминированное слагаемое, которое зависит только от времени, а также импульсные воздействия. Предполагается, что коэффициент диффузии данной системы задается квадратной матрицей, зависящей только от времени. Для изучения рассматриваемых уравнений требуется рассмотрение производных достаточно высоких порядков от свободных членов, включая винеровский процесс. В связи с этим для дифференцирования винеровского процесса мы применяем аппарат производных в среднем по Нельсону от случайных процессов, что позволяет при исследовании уравнения не применять аппарат теории обобщенных функций. В результате получаются аналитические формулы для решений уравнения в терминах производных в среднем случайных процессов.

Ключевые слова: производная в среднем; текущая скоростъ; винеровский процесс; стохастическое уравнение леотьевского типа.

\section{Литература}

1. Шестаков, А.Л. Новый подход к измерению динамически искаженных сигналов / А.Л. Шестаков, Г.А. Свиридюк // Вестник ЮУрГУ. Серия: Математическое моделирование и программирование. - 2010. - № 16 (192), вып. 5. - С. 116-120.

2. Shestakov, A.L. The Theory of Optimal Measurements / A.L. Shestakov, A.V. Keller, G.A. Sviridyuk // Journal of Computational and Engineering Mathematics. - 2014. - V. 1, № 1. - P. 3-16. 
3. Shestakov, A.L. On the Measurement of the «White Noise» / A.L. Shestakov, G.A. Sviridyuk // Вестник ЮУрГУ. Серия: Математическое моделирование и программирование. - 2012. - № 27 (286), вып. 13. - Р. 99-108.

4. Schein, O. Numerical Solution of Stochastic Differential-Algebraic Equations with Applications to Transient Noise Simulation of Microelectronic Circuits / O. Schein, G. Denk // Journal of Computational and Applied Mathematics. - 1998. - V. 100, № 1. - P. 77-92.

5. Sickenberger, T. Stochastic Oscillations in Circuit Simulation / T. Sickenberger, R. Winkler // Proceeding in Applied Mathematics and Mechanics. - 2007. - V. 7, № 1. P. 4050023-4050024.

6. Winkler, R. Stochastic DAEs in Transient Noise Simulation / R. Winkler // Proceedings of Scientific Computing in Electrical Engineering. - 2004. - V. 4. - P. 408-415.

7. Власенко, Л.А. Об одной стохастической модели динамики предприятий корпорации / Л.А. Власенко, Ю.Г. Лысенко, А.Г. Руткас // Экономическая кибернетика. - 2011. № 1-3 (67-69). - C. 4-9.

8. Vlasenko, L.A. On a Stochastic Impulsive Sustem / L.A. Vlasenko, S.L. Lyshko, A.G. Rutkas // Reports of the National Academy of Sciences of Ukraine. - 2012. - № 2. P. 50-55.

9. Белов, А.А. Дескрипторные системы и задачи управления / А.А. Белов, А.П. Курдюков. - М.: Физматлит, 2015.

10. Машков, Е.Ю. Стохастические уравнения леонтьевского типа с коэффициентом диффузии, зависящим от времени / Е.Ю. Машков // Вестник Воронежского государственного университета. Серия: Физика. Математика. - 2017. - № 3. - С. 148-158.

11. Mashkov, E.Yu. Singular Stochastic Leontieff Type Equation with Depending on Time Diffusion Coefficients / E.Yu. Mashkov // Global and Stochastic Analysis. - 2017. - V. 4, № 2. - P. 207-2.517.

12. Nelson, E. Derivation of the Schrödinger Equation from Newtonian Mechanics / E. Nelson // Physics Reviews. - 1966. - V. 150, № 4. - P. 1079-1085.

13. Nelson, E. Dynamical Theory of Brownian Motion / E. Nelson. - Princeton: Princeton University Press, 1967.

14. Nelson, E. Quantum Fluctuations / E. Nelson. - Princeton: Princeton University Press, 1985.

15. Гликлих, Ю.Е. Глобальный и стохастический анализ в задачах математической физики / Ю.Е. Гликлих. - М.: Комкнига, 2005.

16. Gliklikh, Yu.E. Stochastic Leontieff Type Equation with Non-Constant Coefficients Yu.E. Gliklikh, E.Yu. Mashkov // Applicable Analysis: An International Journal. - 2015. V. 94, № 8. - P. 1614-1623.

17. Гликлих, Ю.Е. Стохастические уравнения леонтьевского типа и производные в среднем случайных процессов / Ю.Е. Гликлих, Е.Ю. Машков // Вестник ЮУрГУ. Серия: Математическое моделирование и программирование. - 2013. - Т. 6, № 2. - С. 25-39.

18. Партасарати, K.Р. Введение в теорию вероятностей и теорию меры / K.Р. Партасарати. - М.: Мир, 1988.

19. Гантмахер, Ф.Р. Теория матриц / Ф.Р. Гантмахер. - М.: Физматлит, 1967.

20. Гихман, И.И. Теория случайных процессов / И.И. Гихман, А.В. Скороход. - М.: Наука, 1975 .

Евгений Юрьевич Машков, кандидат физико-математических наук, преподаватель, кафедра «Высшая математика», Юго-Западный государственный университет (г. Курск, Российская Федерация), mashkovevgen@yandex.ru.

Поступила в редакцию 8 марта 2018 г. 